\title{
Armodafinil in the treatment of excessive sleepiness
}

This article was published in the following Dove Press journal:

Nature and Science of Sleep

7 July 2010

Number of times this article has been viewed

\author{
Russell Rosenberg' \\ Richard Bogan² \\ 'NeuroTrials Research, Atlanta, \\ Georgia, USA; ${ }^{2}$ SleepMed of South \\ Carolina, Columbia, South Carolina, \\ USA
}

Correspondence: Russell Rosenberg NeuroTrials Research, I 100 Johnson Ferry Rd, Ste 420, Atlanta, GA 30342, USA

Tel + I $67865 \mathrm{I} 2000$

Fax + I 67865 I 2025

Email russell.rosenberg@atlantasleep.com
Abstract: Excessive sleepiness (ES) is a widespread condition, commonly the result of a sleep/ wake disorder such as obstructive sleep apnea (OSA), shift-work disorder (SWD), or narcolepsy. ES poses significant health and safety concerns in patients. Numerous interventions are available to treat the underlying causes of ES and ES itself, including behavioral measures, mechanical devices, and pharmacologic agents. This review explores the evidence supporting the use of armodafinil to treat ES associated with OSA, SWD, and narcolepsy. Armodafinil is an oral non-amphetamine wake-promoting agent, the $R$-isomer of racemic modafinil. Armodafinil and modafinil share many clinical and pharmacologic properties and are distinct from central nervous system stimulants; however, the mechanisms of action of modafinil and armodafinil are poorly characterized. Compared with modafinil, the wake-promoting effects of armodafinil persist later in the day. It is for this reason that armodafinil may be a particularly appropriate therapy for patients with persistent ES due to OSA, SWD, or narcolepsy.

Keywords: excessive sleepiness, obstructive sleep apnea, shift-work disorder, narcolepsy, wakefulness-promoting agent

\section{Introduction}

Excessive sleepiness (ES) is common and may occur as a consequence of a number of sleep/wake disorders including obstructive sleep apnea (OSA), shift-work disorder (SWD), narcolepsy, and jet lag. Although the full extent of its prevalence has not been established, ES is known to be widespread, in part because of the large number of people who are required to perform shift work, work for prolonged periods, or regularly participate in transmeridian flight. ${ }^{1}$ Findings from the National Sleep Foundation's 2008 Sleep in America Poll ${ }^{2}$ point to a large proportion of working Americans being affected by a lack of sleep, with $15 \%$ of the 1000 respondents having been diagnosed with a sleep/wake disorder. This poll also revealed that $29 \%$ of respondents had slept or been drowsy at work in the past month and that $36 \%$ had fallen asleep while driving in the past year. ${ }^{2}$

ES may also arise because of insufficient night-time sleep due to behavioral issues (eg, self-imposed sleep deprivation or poor sleep hygiene), psychiatric conditions, medication, or medical conditions other than sleep/wake disorders. ${ }^{3}$ Sleep hygiene refers to elements intended to create a mental and environmental state conducive to sleep, eg, a regular sleep/wake pattern, avoidance of stimulants such as caffeine and nicotine close to bedtime, and having a quiet, peaceful place to sleep. ${ }^{4,5}$ The co-existence of psychiatric disorders and ES is common. ${ }^{6}$ For example, depression often interferes with sleep behavior and thus the quality of sleep. The side effects of a wide variety submit your manuscript | www.dovepress.com

Dovepress

6728 
of medications, such as benzodiazepines and antihistamines, can cause ES. ${ }^{3}$ A number of medical conditions can affect the duration and quality of sleep, such as those that interfere with breathing (eg, nasal congestion and chronic obstructive pulmonary disease), Parkinson's disease, movement disorders, and chronic pain syndromes. ${ }^{7}$ Both quality and quantity of sleep are important factors in ensuring that an individual feels rested and alert and poor sleep quality in particular has been found to be related to the development of ES. ${ }^{8}$

This review will discuss the prevalence and management of ES before moving on to its main focus - the use of the wake-promoting agent armodafinil in the treatment of ES. Armodafinil has been approved in the United States for the treatment of patients with ES associated with treated OSA, SWD, and narcolepsy.

\section{Consequences of ES}

ES affects not only patients' health but also their ability to work and drive safely and the extent to which they can function and enjoy day-to-day living.

\section{Clinical consequences}

ES is associated with increased rates of cardiovascular mortality, myocardial infarction, and congestive heart failure. ${ }^{9}$ Moreover, patients with OSA and associated ES are at a higher risk of developing ischemic heart disease than patients who have OSA in isolation. ${ }^{10}$ Patients with ES are also more likely to develop diabetes than those without ES and, on average, have a higher body mass index; both diabetes and high BMI are characteristics of metabolic syndrome. ${ }^{11}$ The relationship between OSA, ES, and metabolic syndrome is complex; however, it is thought that these individual factors interact and exacerbate each other, putting the patient at greater risk for further complications. ${ }^{11}$

ES can lead to significant cognitive sequelae, affecting both attention and memory. ${ }^{12}$ Patients with ES associated with OSA or shift work are particularly susceptible to reductions in cognitive functioning. ${ }^{13}$ Depression and ES have a complex and reciprocal relationship: sleep disruption associated with depression can lead patients to experience ES, while mental, social, and work issues caused by persistent ES can also trigger depression. ${ }^{11}$

\section{Workplace and driving consequences}

Individuals with ES associated with OSA are at an increased risk for recent work disability (adjusted odds ratio 13.7; 95\% confidence interval [CI], 3.9-48.0) or a work role change due to a lack of coping/poor performance (odds ratio 3.6;
95\% CI, 1.1-12.0) compared with individuals without this sleep disorder. ${ }^{14}$ Moreover, the occurrence of absenteeism is elevated in individuals with ES and is further exacerbated by shift work. ${ }^{15}$ According to a survey of occupational accidents occurring in the United States in 1988, ES was implicated in $52.5 \%$ of all work-related accidents, amounting to an estimated cost of $\$ 24.7$ billion (based on 1994 calculations; $\$ 36.1$ billion when adjusted to 2009 values). ${ }^{16}$

There is substantial evidence that ES contributes to many road traffic crashes, with a survey conducted in the UK revealing that $17 \%$ of collisions resulting in injury or death are sleep related. ${ }^{17}$ This survey also revealed that sleep-related collisions are approximately 50\% more likely to result in death or serious injury than other road traffic crashes. ${ }^{17}$ A review of traffic safety in relation to sleep/wake disorders and ES listed changes in attention and information processing, changes in sensation and perception, "highway hypnosis," and microsleeping as consequences of ES that led to poor driver performance. ${ }^{18}$ A combined field and laboratory study by the US Department of Transportation has revealed that many long-haul commercial drivers nap during shiftwork hours and spend a significant part of their time at the wheel in a state of sleep deprivation. ${ }^{19}$

\section{Quality of life}

A recent analysis of 1892 adults with untreated OSA revealed that quality of life (QOL) not only worsened with the severity of the condition, but that it was also at its lowest in those with ES. ${ }^{20}$ In this study, all domains of the Medical Outcomes Study Short-Form (36-item) Health Survey (SF-36) were significantly negatively affected by $\mathrm{ES}(P<0.05) .{ }^{20} \mathrm{ES}$ is also detrimental to QOL in patients with narcolepsy. ${ }^{21,22}$ In particular, patients with narcolepsy and cataplexy report that ES has a significant negative impact on the role physical subscale of the SF-36. ${ }^{22}$ Earlier studies have also highlighted the impact of ES on patients' everyday lives, reporting that patients with sleep-disordered breathing and ES have lower scores on all subscales of the SF-36 when compared with patients who are not excessively sleepy. ${ }^{23-26}$

\section{Management of ES}

ES is an underrecognized and undertreated condition, in part because it may not be perceived as a serious problem and hence is not disclosed by patients. ${ }^{3}$ Patients may not recognize their ES at all or describe it to their physician as tiredness, fatigue, difficulty concentrating, or a lack of energy. ${ }^{27}$ In addition, ES can be misdiagnosed as depression owing to shared signs such as a lack of motivation, memory disturbances, and diminished 
interest in activities of daily living. ${ }^{3}$ To aid in the recognition of ES and potential causative sleep/wake disorders, physicians can ask questions regarding the patient's sleep quality, assess alertness using simple subjective measures, such as the Epworth Sleepiness Scale (ESS), or use objective measures of ES, such as the Multiple Sleep Latency Test (MSLT) or Maintenance of Wakefulness Test (MWT). ${ }^{28-30}$ The ESS is the most widely adopted instrument and is useful for identifying ES in clinical practice, particularly in the primary care setting, and is appropriate for monitoring self-reported responses to management/ treatment approaches. ${ }^{28}$ The MSLT and MWT are most often used by sleep specialists and measure a patient's ability to fall asleep or remain awake, respectively. ${ }^{29,30}$ Additional information that a healthcare professional might seek for the identification of ES includes the following: the number of hours of sleep that the patient gets on most nights; whether the patient snores or holds their breath during sleep; whether the patients wake up feeling refreshed most mornings; whether the patient is sleepy or fatigued during waking hours; and whether the patient works night or rotating shifts.

Strategies for the management of ES should begin with an initial assessment to identify the cause of ES and, where possible, to treat any underlying disorder. In many cases, all that may be required is education regarding proper sleep hygiene, in particular, maintaining a regular schedule of activities. ${ }^{5}$ However, mechanical interventions and/or medication are often necessary to address conditions such as OSA, SWD, or narcolepsy.

\section{Management of sleep/wake disorders causative of ES Obstructive sleep apnea}

OSA is characterized by intermittent full or partial obstruction of the upper airway during sleep leading to abnormal breathing and repetitive episodes of arousal. ${ }^{31}$ OSA with associated ES is the most frequently reported sleep-related breathing disorder, with an estimated prevalence in the United States of $4 \%$ and $2 \%$ in middle-aged men and women, respectively. ${ }^{32}$ Individuals with OSA complain of unrefreshing sleep, ES during the day, low mood, and an inability to concentrate. ${ }^{33}$

Continuous positive airway pressure (CPAP) therapy is the gold standard treatment for OSA. The CPAP device ensures that the airway remains open, reducing the arousals from sleep that can occur as a consequence of airway collapse and reduced blood oxygen levels. ${ }^{34}$ Unfortunately, objective ES (as measured using the MSLT) persists in approximately $50 \%$ of patients, even when abnormal respiratory events are optimally treated with $\geq 6$ hours of CPAP per night. ${ }^{35}$ The wakefulness-promoting agent modafinil is recommended by the American Academy of Sleep Medicine (AASM) for the treatment of residual ES in patients with treated OSA. ${ }^{36}$ Modafinil and its enantiomer armodafinil are approved by the US Food and Drug Administration (FDA) for this indication, based on the results of several large-scale clinical trials. ${ }^{37-41}$ As armodafinil is a comparatively new medication, it has not yet been incorporated into AASM guidelines for the treatment of ES associated with treated OSA. Stimulants, such as amphetamines, reverse the daytime somnolence seen in some patients on CPAP therapy; however, these agents carry a potential risk for abuse and cardiovascular sequelae and further evidence is required before they can be recommended in this indication. . $33,36^{-3}$

\section{Shift-work disorder}

The homeostatic drive for sleep intensifies with increasing time since the last rest period and is offset during daylight hours by circadian wake-promoting processes. Shift-work schedules cause misalignment of the sleep/wake pattern so that the homeostatic drive for sleep is no longer counteracted by the body's endogenous circadian rhythm. ${ }^{31,42}$ SWD is diagnosed by persistent insomnia when trying to sleep and/or ES when trying to stay awake - these symptoms must coincide with the affected individual's working shifts. ${ }^{31}$ Approximately 22 million Americans regularly work night, early morning, or rotating shifts ${ }^{43}$ and SWD has become a common - although underrecognized - condition as a result. In a US study, $44.8 \%$ of night-shift workers and $35.8 \%$ of rotating-shift workers were reported to have SWD (as assessed by an ESS score of $\geq 10$ ), which suggests that up to $45 \%$ of individuals who work shifts may be at risk of developing SWD. ${ }^{15}$ More recently, a study of United Kingdom North Sea oil rig workers has reported that $23 \%$ of shift workers have SWD. ${ }^{44}$

The treatment of SWD encompasses a number of interventions including nonpharmacologic measures, such as improving sleep hygiene, light therapy, and planned nap times. ${ }^{42}$ Modafinil and armodafinil are FDA approved for the treatment of ES associated with SWD. These non-stimulant wakefulness-promoting agents significantly increased sleep latencies in randomized controlled trials conducted specifically in patients with SWD. ${ }^{45-47}$ Other pharmacologic options, including melatonin and hypnotics such as zolpidem (to improve daytime sleep) and stimulants such as methamphetamine (to improve night-time alertness), have had varying degrees of success in promoting sleep or wake in shift workers. ${ }^{1,48}$ However, studies of these agents in SWD are limited, making it difficult to draw firm conclusions as to their utility in patients with this sleep disorder. ${ }^{42}$ 


\section{Narcolepsy}

Narcolepsy occurs in $<1 \%$ of individuals in the United States $^{49}$ and is characterized by ES that varies in intensity throughout the day, such that the affected individual has to take frequent naps. ${ }^{31}$ Indeed, narcolepsy often results in unanticipated sleep episodes lasting from a few seconds to several minutes during periods of reduced stimulation. ${ }^{3}$

The intrinsic dysfunction in sleep regulation that causes ES in narcolepsy often requires pharmacotherapy to enhance wakefulness. Methylphenidate and dextroamphetamine are approved in this indication, although these medications have the potential for abuse and their use should therefore be monitored closely. ${ }^{50}$ Sodium oxybate has been shown to significantly reduce ES and cataplexy in patients with narcolepsy in randomized clinical trials and it is the only FDA-approved medication for the treatment of both of these symptoms. ${ }^{51-54}$ Modafinil and armodafinil have been shown to address ES in patients with narcolepsy in randomized controlled trials ${ }^{55-57}$ and are approved by the FDA for this indication.

\section{Armodafinil}

Armodafinil and its use in the three indications described above will be the focus of the remainder of this article.

\section{Pharmacology}

Armodafinil (2-[R-(diphenylmethyl)sulfinyl]acetamide; Figure 1$)$ is the $R$-enantiomer of racemic modafinil and shares many of the properties and characteristics of modafinil. Like modafinil, armodafinil is an orally administered wake-promoting agent that is clinically and pharmacologically distinct from central nervous system stimulants. ${ }^{58,59}$
A

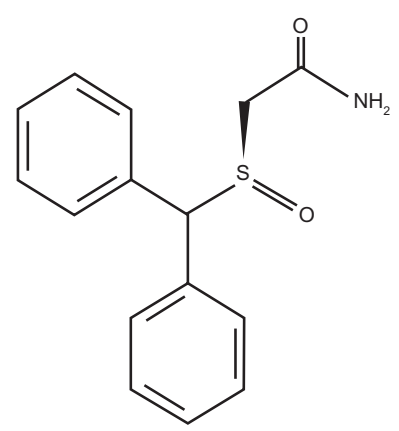

B

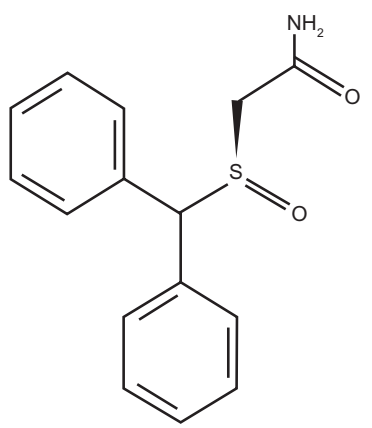

Figure I Structure of (A) R-modafinil and (B) S-modafinil. Armodafinil comprises only $R$-modafinil, while racemic modafinil comprises a mixture of both $R$ - and S-modafinil.

\section{Pharmacodynamics}

The modes of action of armodafinil and modafinil are currently not fully understood, although it is likely that they involve selective effects on catecholaminergic signaling in the central nervous system via dopaminergic, noradrenergic, and serotonergic receptors. ${ }^{60-62}$ These effects are not well defined and despite ex-vivo assays showing binding of modafinil to the dopamine transporter and inhibition of dopamine reuptake, modafinil is not a direct or an indirect dopamine receptor agonist. ${ }^{63}$ Hypocretin (or orexin)-producing neurons within the hypothalamus (postulated as preventing inappropriate changes in consciousness) are believed to be activated by modafinil to release dopamine and norepinephrine to promote wakefulness,${ }^{64}$ and this activity may also account for the observed clinical effect of armodafinil. ${ }^{61,62}$ Furthermore, modafinil may potentiate wakefulness by increasing electrical coupling at gap junctions between neurons. ${ }^{65}$

\section{Pharmacokinetics}

A $200 \mathrm{mg}$ dose of armodafinil, when administered orally, is readily absorbed, with a maximum plasma drug concentration of $5.44 \pm 1.64 \mu \mathrm{g} / \mathrm{mL}$ being achieved in approximately 2 hours. ${ }^{66}$ These values are comparable with those for modafinil (Table 1). With once-daily dosing, armodafinil reaches its steady state after approximately 7 days. ${ }^{67}$ The bioavailability of armodafinil is unaffected by food, although the rate of absorption is delayed by approximately $2-4$ hours when armodafinil is taken postprandially. ${ }^{67}$ Armodafinil is widely distributed outside the vascular system, but it does not have a high affinity for tissues ${ }^{67}$ It is unlikely to interact with highly protein-bound drugs, although it does bind with albumin to a moderate degree. ${ }^{63}$

Armodafinil is metabolized by amide hydrolysis followed by sulfone formation via the cytochrome P450 (CYP) 3A4/5 enzyme pathway. ${ }^{63}$ Dosage adjustment to sustain clinical efficacy may be necessary if patients are receiving concomitant medications that are also metabolized via this pathway (eg, steroidal contraceptives, cyclosporine, midazolam, and triazolam).${ }^{63}$ Like modafinil, armodafinil moderately inhibits the activity of CYP2C19, and medications that are metabolized via this enzyme (eg, diazepam) may display prolonged elimination, requiring lower doses of these agents to be administered when given concomitantly with armodafinil. ${ }^{68}$

Elimination of armodafinil is monophasic with a mean elimination half-life of approximately 15 hours. ${ }^{67}$ This contrasts with the elimination half-life of the $S$-enantiomer, which is approximately three- to fourfold shorter than that of armodafinil and is responsible for racemic modafinil's 
Table I Pharmacokinetic parameters of armodafinil and modafinil

\begin{tabular}{lll}
\hline Parameters & $\begin{array}{l}\text { Armodafinil 200 mg } \\
\text { (mean } \pm \text { SD) }\end{array}$ & $\begin{array}{l}\text { Modafinil 200 mg } \\
\text { (mean } \pm \text { SD) }\end{array}$ \\
\hline $\mathrm{C}_{\max }(\mu \mathrm{g} / \mathrm{mL})$ & $5.44 \pm \mathrm{I} .64$ & $4.6 \mathrm{I} \pm 0.73$ \\
$\mathrm{AUC}_{\text {last }}(\mu \mathrm{g} \cdot \mathrm{h} / \mathrm{mL})$ & $88.2 \pm 29.6$ & $66.5 \pm \mathrm{I} 4.4$ \\
$\mathrm{AUC}_{\infty}(\mu \mathrm{g} \cdot \mathrm{h} / \mathrm{mL})$ & $95.8 \pm 28.0$ & $68.5 \pm 15.3$ \\
$t_{\max }(\mathrm{h})^{\mathrm{a}}$ & 1.8 & 2.5 \\
$t_{1 / 2 \beta}(\mathrm{h})$ & $13.0 \pm 2.6$ & $13.6 \pm 2.0$ \\
\hline
\end{tabular}

Note: a Median values.

Reprinted with permission from Darwish M, Kirby M, Hellriegel ET, Robertson P Jr. Armodafinil and modafinil have substantially different pharmacokinetic profiles despite having the same terminal half lives: analysis of data from three randomized, single-dose, pharmacokinetic studies. Clin Drug Investig. 2009;29(9):613-623. ${ }^{.6}$ Copyright (C 2009 Wolters Kluwer.

Abbreviations: $A \cup C_{\text {last }}$, area under the plasma drug concentration vs time curve from time zero to the time of the last measurable concentration; $A \cup C_{\infty}$, area under the plasma drug concentration vs time curve from time zero to infinity $C_{\text {max }}$, maximum plasma drug concentration; $S D$, standard deviation; $t_{1 / 2 \beta}$, termina elimination half-life; $t_{\max }$, time to reach $C_{\max }$

biphasic elimination profile. As a consequence of their different elimination profiles, armodafinil is present at higher concentrations than modafinil from 4-6 hours after administration. ${ }^{67}$ Greater systemic availability of armodafinil compared with modafinil on a milligram-by-milligram basis (as indicated by a markedly greater area under the plasma drug concentration-time curve [Table 1]) may result in improved wakefulness later in the day in individuals with ES. ${ }^{66}$

Dose reductions of armodafinil should be considered in patients with severe hepatic impairment owing to a reduction in observed oral clearance and an increase in the steady-state concentration of modafinil in this patient group. ${ }^{63}$ Similarly, dose reductions should be considered in elderly patients in whom elimination may be delayed.

\section{Efficacy of armodafinil}

In preclinical studies, a rat model of sleep deprivation was used to explore the efficacy of armodafinil in comparison with the stimulant D-methamphetamine for promoting wakefulness. ${ }^{69}$ The agents had equivalent wakefulness-promoting effects, as measured by their impact on sleep/wake patterns and body temperature. However, unlike D-methamphetamine, armodafinil did not induce symptoms of sleep deprivation such as acute rebound hypersomnolence. ${ }^{69}$

To date, the only head-to-head study of armodafinil and modafinil was performed using healthy subjects. ${ }^{70}$ Based on direct comparison of their pharmacokinetic/pharmacodynamic profiles, the prolonged half-life of armodafinil may be associated with improved wakefulness and sustained attention for a longer time after dosing than modafinil. ${ }^{70}$ When administered as single doses to sleep-deprived healthy volunteers, both armodafinil and modafinil demonstrated significant wakefulness-promoting effects compared with placebo. ${ }^{70}$ Using the MWT to measure sustained wakefulness and the Psychomotor Vigilance Task to measure sustained attention (ie, vigilance and reaction time), armodafinil and modafinil had significant positive effects on these parameters $(P<$ 0.0001 for both agents in both tests). However, compared with modafinil, armodafinil treatment resulted in fewer lapses in wakefulness and attention between 6 and 13.5 hours after administration, indicating that armodafinil may have comparatively prolonged effects. ${ }^{70}$ Armodafinil may therefore represent a useful pharmacologic option for patients with ES associated with OSA, SWD, or narcolepsy who wish to stave off sleepiness for long periods.

\section{Armodafinil for the treatment of ES associated with OSA}

Two Phase 3 studies, which together randomized $>650$ patients with OSA to treatment, have compared the efficacy and safety of armodafinil and placebo (Table 2). ${ }^{38,39}$ The patients enrolled in these studies had residual ES despite use of appropriately titrated CPAP therapy and were randomized to receive armodafinil $150 \mathrm{mg}$ /day or placebo ${ }^{38}$ or armodafinil 150 or $250 \mathrm{mg} /$ day or placebo. ${ }^{39}$ The results of these studies have also been reported in a combined analysis. ${ }^{40}$

Armodafinil was associated with a significant increase in mean sleep latency from baseline to the final visit at week 12 as measured using the MWT in all studies. In the study by Roth et al ${ }^{39}$ the mean change in sleep latency at the final visit was +1.9 minutes with armodafinil vs -1.7 minutes in patients given placebo $(P<0.001)$. In the study conducted by Hirshkowitz et al ${ }^{38}$ patients receiving armodafinil experienced an increase in sleep latency of +2.3 minutes vs -1.3 minutes in those given placebo $(P<0.001)$. The combined analysis ${ }^{40}$ reported that sleep latency increased by 2.0 minutes in patients administered armodafinil and decreased by 1.5 minutes in patients given placebo $(P<0.0001$; Table 2$)$. Nighttime sleep was not adversely affected by armodafinil and patients' compliance with CPAP therapy was high (a mean of approximately 7 hours/night). In addition, armodafinil had sustained benefits late in the waking day compared with placebo, as demonstrated by higher MWT scores at 15:00, 17:00, and 19:00 hours. ${ }^{40}$

Improrements in patients' clinical condition (evaluated using the Clinical Global Impression of Change scale [CGI-C]) were significantly greater in the armodafiniltreated group than in the placebo group $(P<0.001)$ at all timepoints in the study of patients with OSA performed by Roth et al. ${ }^{39}$ Similarly in the second OSA study conducted by Hirshkowitz et al ${ }^{38}$ the proportion of patients with at 
Table 2 Wakefulness-promoting effects of armodafinil in the treatment of ES associated with OSA, SWD, and narcolepsy

\begin{tabular}{|c|c|c|c|}
\hline Study/indication & Patients (n) & Treatment & Wakefulness \\
\hline \multicolumn{4}{|l|}{ OSA } \\
\hline \multirow[t]{3}{*}{ Hirshkowitz et al ${ }^{38}$} & 259 & & MWT \\
\hline & & Armodafinil (I50 mg/day) & $+2.3 \min$ \\
\hline & & Placebo & $-1.3 \min (P<0.001)$ \\
\hline \multirow[t]{3}{*}{ Roth et $\mathrm{al}^{39}$} & 395 & & MWT \\
\hline & & Armodafinil (I50/250 mg/day) & $+1.9 \mathrm{~min}$ \\
\hline & & Placebo & $-1.7 \min (P<0.001)$ \\
\hline \multirow[t]{3}{*}{ Roth et $\mathrm{al}^{40}$} & 658 & & MWT \\
\hline & & Armodafinil (I50/250 mg/day) & $+2.0 \mathrm{~min}$ \\
\hline & & Placebo & $-1.5 \min (P<0.0001)$ \\
\hline \multicolumn{4}{|l|}{ SWD } \\
\hline \multirow{3}{*}{ Czeisler et al ${ }^{46}$} & 245 & & MSLT \\
\hline & & Armodafinil ( $150 \mathrm{mg} /$ day $)$ & $+3.1 \mathrm{~min}$ \\
\hline & & Placebo (given 30-60 min before the shift) & $+0.4 \min (P<0.001)$ \\
\hline \multicolumn{4}{|l|}{ Narcolepsy } \\
\hline \multirow[t]{5}{*}{ Harsh et $\mathrm{a}^{55}$} & 194 & & MWT \\
\hline & & Armodafinil ( $150 / 250$ mg/day) & 09:00-15:00: +1.9 min \\
\hline & & & $15: 00-19: 00:+1.6 \min$ \\
\hline & & Placebo & $\begin{array}{l}\text { 09:00-15:00: }-1.9 \min (P<0.01 \text { vs armodafinil } \\
\text { combined })\end{array}$ \\
\hline & & & $\begin{array}{l}\text { I5:00-19:00: }-1.2 \min (P<0.05 \text { vs armodafinil } \\
\text { combined })\end{array}$ \\
\hline
\end{tabular}

Abbreviations: ES, excessive sleepiness; MSLT, Multiple Sleep Latency Test; MWT, Maintenance of Wakefulness Test; OSA, obstructive sleep apnea; SWD, shift-work disorder.

least minimal improvement in their clinical condition at the final visit was significantly higher in the armodafinil group compared with the placebo group $(P<0.01)$.

Cognitive performance was significantly improved with armodafinil compared with placebo in patients with OSA. ${ }^{40}$ The Cognitive Drug Research battery of tests was used to assess cognitive performance (memory and attention) at six timepoints during the day; the mean ( \pm standard deviation) change from baseline in quality of long-term episodic secondary memory at the final visit was $10.2( \pm 31.7)$ units for the armodafinil group compared with $-0.7( \pm 46.3)$ units for the placebo group $(P<0.01){ }^{40}$

\section{Armodafinil for the treatment of ES in patients with SWD}

Armodafinil displayed significant benefits compared with placebo in a 12-week phase 3, randomized, double-blind, multicenter study of 245 patients with SWD (Table 2). ${ }^{46}$ Subjects included in this study were permanent or rotating night-shift workers with SWD who worked $\geq 5$ nights per month, had a mean sleep latency of $\leq 6 \mathrm{~min}$ (as assessed using the MSLT), and had experienced ES during night shifts for $\geq 3$ months. ${ }^{46}$

Patients in this study had baseline mean sleep latencies of 2.3 and 2.4 minutes in the armodafinil and placebo groups, respectively; both values indicate severe sleepiness.
At the end of the study, patients in the armodafinil group had significantly increased sleep latencies compared with the placebo group (3.1 vs 0.4 minutes, respectively; $P<0.001) .{ }^{46}$ At the final visit, CGI-Improvement ratings were improved in a significantly greater proportion of patients in the armodafinil group compared with the placebo group (79\% vs 59\%, respectively; $P=0.001) .{ }^{46}$ In addition, at the final visit, armodafinil significantly improved the quality of episodic secondary memory and the power and continuity of attention compared with placebo (all $P \leq 0.001){ }^{46}$

\section{Armodafinil for ES in patients with narcolepsy}

The efficacy and safety of armodafinil for the treatment of ES in narcolepsy were demonstrated in a phase 3, placebocontrolled study of 194 patients (Table 2). ${ }^{55}$ In this study, patients were randomized to receive armodafinil 150 or $250 \mathrm{mg} /$ day or placebo for 12 weeks.

Daytime (09:00-15:00 hours) sleep tendency assessed using the MWT was found to be significantly improved with armodafinil (+1.9 minutes for both armodafinil groups combined) relative to placebo $(-1.9$ minutes; $P<0.01)$. These benefits were sustained late in the waking day (15:00-19:00 hours) as demonstrated by sleep latency improvements from baseline of 1.6 minutes for both armodafinil groups combined, while 
a reduction of 1.2 minutes was observed in patients in the placebo group $(P<0.05$ vs armodafinil $) .{ }^{55}$

At the final visit, the proportion of patients who had at least minimal improvement in their CGI-C ratings was significantly higher in the active-treatment groups compared with placebo $(P<0.0001) .{ }^{55}$ Armodafinil demonstrated significant improvements compared with placebo in power of attention, quality of episodic secondary memory, and speed of memory (all $P<0.05) .{ }^{55}$ Improvements were observed at the week 4 visit and were maintained throughout the 12-week study period.

\section{Open-label studies}

Two noncomparative open-label studies of armodafinil that focused primarily on patient-reported outcomes have also been completed. These studies enrolled 1071 patients with OSA, SWD, or narcolepsy. One study ${ }^{71}$ exclusively enrolled patients who had taken part in any of the aforementioned placebo-controlled, double-blind studies, while the other was also open to subjects who had not participated in the earlier trials. ${ }^{72}$ Patients' overall clinical condition was significantly improved with armodafinil compared with baseline values. ${ }^{71,72}$ At the final visit, between $75 \%$ and $98 \%$ of patients with OSA, narcolepsy, or SWD were deemed to have at least a minimal clinical improvement according to CGI-C ratings. ${ }^{71,72}$ Furthermore, $66 \%$ of armodafinil-treated patients with ES associated with OSA or narcolepsy perceived their clinical condition as "very much improved" or "much improved."73

\section{Impact of armodafinil on patient-focused outcomes}

As ES associated with sleep/wake disorders has such a serious impact on patients' daily lives, it is important to assess armodafinil's treatment effects from the patient's perspective. Armodafinil has been studied with regard to a number of patient-focused aspects.

\section{Subjective sleepiness}

In clinical studies of armodafinil, ES has been measured subjectively using either the ESS or the Karolinska Sleepiness Scale (KSS). ESS scores in patients with treated OSA and residual ES showed that almost half (49\%) of patients in the armodafinil group responded to treatment compared with one-quarter $(26 \%)$ of patients in the placebo group..$^{40}$ Use of the ESS also enabled investigators to establish that patients with ES associated with OSA treated with armodafinil expe- rienced improvements in their ability to engage in activities of daily living at all study visits $(P<0.0001) .{ }^{40}$ Furthermore, armodafinil significantly improved ESS scores compared with placebo in patients with OSA $(P<0.01){ }^{74}$

Armodafinil was effective in reducing subjective ES in patients with narcolepsy. ${ }^{55}$ At the final visit, 21\%, 25\%, and $7 \%$ of patients with narcolepsy who were given armodafinil $150 \mathrm{mg}$, armodafinil $250 \mathrm{mg}$, or placebo, respectively, had an ESS score indicative of normal alertness $(P<0.05){ }^{55}$

The KSS is particularly useful for assessing the intrusion of sleep into states of wakefulness. ${ }^{75}$ Using the KSS, patients with SWD treated with armodafinil reported a significant reduction in ES at week 12 compared with those given placebo $(P \leq 0.01){ }^{46}$

Data derived from electronic diaries completed by patients with SWD revealed that armodafinil significantly reduced maximum ES during the night shift $(P<0.001$ vs placebo) and demonstrated that armodafinil was associated with a twofold reduction in ES during the commute home $(P<0.01$ vs placebo $) .{ }^{46}$ Electronic diaries used in a study of patients with narcolepsy revealed that armodafinil reduced the number of unintended daily sleep episodes by between $33 \%$ and $44 \%$ compared with $10 \%$ in the placebo group $(P<0.0001) .{ }^{55}$ In addition, the mean number of daily naps were reduced by between $41 \%$ and $44 \%$ in the armodafiniltreated group compared with $22 \%$ in patients who received placebo $(P<0.01){ }^{55}$

\section{Fatigue}

In a study of patients with OSA-associated ES with or without depression, a significant reduction in fatigue $(P<0.01)$ was reported by armodafinil-treated patients vs the placebo group when assessed using the Brief Fatigue Inventory (BFI). ${ }^{76}$ Patients with narcolepsy have also reported significantly better relief from the fatigue associated with ES $(P<0.001)$ when treated with armodafinil vs placebo. ${ }^{55} \mathrm{In}$ an open-label extension study of patients with OSA, SWD, or narcolepsy, armodafinil was associated with an overall improvement from baseline in fatigue and a reduction in worst fatigue, as measured using the BFI. ${ }^{71}$

\section{Quality of life}

Although data on the impact of armodafinil on patients' QOL have not been explicitly reported, $71 \%$ of patients who were administered armodafinil in a recent open-label study reported an improved ability to engage in daily activities. ${ }^{73}$ The improvements seen in patient-reported outcomes, 
including subjective ES, cognitive function, and fatigue, are likely to have a positive impact on patients' lives and well-being.

\section{Safety and tolerability of armodafinil}

Armodafinil was generally well tolerated in randomized trials and open-label extension studies of patients with OSA, SWD, or narcolepsy. ${ }^{40,46,55,71,72}$ Adverse events were reported to be mild to moderate in intensity, with the most common events being headache, nasopharyngitis, anxiety, and insomnia. ${ }^{40,46,55,71}$ In the randomized studies of patients with OSA, narcolepsy, and SWD, headache occurred in $17 \%, 22 \%$, and $12 \%$ of these patients, respectively (Table 3). ${ }^{40,46,55}$ In the two open-label studies, headache occurred in $17 \%{ }^{72}$ and $25 \%{ }^{71}$ of patients. Overall, no clinically meaningful changes in mean laboratory variables, vital sign measurements, electrocardiogram, or physical examination findings were reported for patients treated with armodafinil. ${ }^{72}$

Patient compliance with armodafinil therapy was good, with similar discontinuation rates to those reported with placebo. ${ }^{77}$ Of the patients treated with armodafinil in the randomized trials, less than $12 \%$ in any study withdrew from study treatment because of an emergent adverse event. Approximately $6 \%$ of patients who received placebo in these studies withdrew due to adverse events..$^{38-40,55}$

\section{Conclusions}

The personal, social, and economic implications of ES associated with OSA, SWD, or narcolepsy are immense, putting individu-

Table 3 The most commonly reported adverse events ( $\geq 5 \%$ of patients) occurring in patients with OSA, narcolepsy, or SWD treated with armodafinil (I 50 or $250 \mathrm{mg} /$ day) ${ }^{40,46,55}$

\begin{tabular}{|c|c|c|c|}
\hline \multirow[t]{2}{*}{ Indications } & \multirow{2}{*}{$\begin{array}{l}\text { Adverse } \\
\text { events }\end{array}$} & \multicolumn{2}{|l|}{ Incidence (\%) } \\
\hline & & $\begin{array}{l}\text { Armodafinil } \\
\text { (150/250 mg) }\end{array}$ & Placebo \\
\hline \multirow[t]{6}{*}{ OSA } & & $(n=39 I)$ & $(n=260)$ \\
\hline & Headache & 17 & 8 \\
\hline & Nausea & 6 & 4 \\
\hline & Insomnia & 6 & 1 \\
\hline & Dizziness & 5 & 2 \\
\hline & Anxiety & 5 & $<1$ \\
\hline \multirow[t]{4}{*}{ Narcolepsy } & & $(n=|3|)$ & $(n=63)$ \\
\hline & Headache & 22 & II \\
\hline & Nausea & II & 0 \\
\hline & Dizziness & 5 & 0 \\
\hline \multirow[t]{5}{*}{ SWD } & & $(n=123)$ & $(n=122)$ \\
\hline & Headache & 12 & 10 \\
\hline & Nausea & 7 & 3 \\
\hline & Nasopharyngitis & 6 & 3 \\
\hline & Anxiety & 5 & 2 \\
\hline
\end{tabular}

Abbreviations: OSA, obstructive sleep apnea; SWD, shift-work disorder. als at increased risk for serious health problems, work-related accidents, and road traffic crashes. Treating the underlying cause of ES in patients is vital in order to address this potentially serious issue. However, pharmacotherapy may be required in patients who experience residual ES despite adequate therapy for OSA and in those who have narcolepsy-related ES. Furthermore, some patients who experience ES as a symptom of SWD may not be able to alter their work schedule and may not find their condition abates with behavioral treatments; such patients may, therefore, also require medication to remain wakeful.

The clinical trial results reported herein indicate that armodafinil produces statistically and clinically significant reductions in ES in patients with OSA, SWD, and narcolepsy. For example, a mean sleep latency of $\leq 5$ minutes, as measured using the MSLT, is considered pathological. In the study by Czeisler et al, ${ }^{46}$ enrolled patients with SWD had a mean sleep latency of 2.3-2.4 minutes at baseline, which was improved to $>5$ minutes (above the cutoff for pathological sleepiness) at the final visit in patients given armodafinil. This $>3$-minute increase in sleep latency indicates that the biologic sleep drive of these patients has diminished and that their general functionality has improved. In addition, findings from these randomized and open-label clinical studies show armodafinil to be well tolerated with mild to moderate adverse events. Armodafinil may also improve memory and attention in patients with ES. ${ }^{40,46}$ Moreover, the wakefulness-promoting effects of armodafinil are of a similar magnitude to those of modafinil. However, the effects of armodafinil may persist for longer than those of modafinil, ${ }^{70}$ indicating that armodafinil is a useful option for patients who may wish to remain alert later in the day.

Studies of the effect of armodafinil on ES in other patient groups are ongoing or planned and include patients with mild or moderate closed traumatic brain injury (NCT00893789) and patients with sarcoidosis (NCT00555347). Armodafinil is also being investigated as a treatment for jet lag and initial results have been favorable in this indication. ${ }^{78}$ Further studies of armodafinil may expand its clinical value; however, more safety and efficacy studies are required before armodafinil can be recommended for promoting wakefulness in a wider context, such as instances where public safety or welfare may be an issue. Additional research to elucidate how armodafinil (and modafinil) promote wakefulness would be beneficial, as the mechanisms of action of these agents remain poorly understood at this time.

\section{Acknowledgments}

Editorial support was provided by Jane Bryant of Anthemis Consulting Ltd and was funded by Cephalon Inc, Frazer, PA, 
who provided a medical accuracy review. The authors were not compensated and retained full editorial control over the content of the paper.

\section{Disclosures}

Dr Rosenberg has received research funding from Cephalon Inc, Pfizer Inc, sanofi-aventis, Respironics, Neurogen, Vanda Pharmaceuticals, Merck, and GlaxoSmithKline.

Dr Bogan is a shareholder and employee of SleepMed Inc.; acts as a consultant to Cephalon Inc., GlaxoSmithKline, and Jazz Pharmaceuticals; has conducted industry-funded research for Actelion Pharmaceuticals Ltd, Addrenex Pharmaceuticals Inc., Apnicure Inc., Arena Pharmaceuticals Inc., Boehringer Ingelheim, Cephalon Inc., Evotec, GlaxoSmithKline, Jazz Pharmaceuticals, Johnson and Johnson, Eli Lilly and Co., Merck \& Co. Inc., Neurogen Corporation, Novartis, Philips, Pfizer Inc., ResMed, sanofi-aventis, Schwarz Pharma, Sensory Medical Inc., Sepracor Inc., Vanda Pharmaceuticals Inc., Ventus Medical, and XenoPort Inc.; and has taken part in speaker bureau engagements for Cephalon Inc., Jazz Pharmaceuticals. sanofi-aventis, and Sepracor Inc.

\section{References}

1. Sack RL, Auckley D, Auger RR, et al. Circadian rhythm sleep disorders: part I, basic principles, shift work and jet lag disorders. An American Academy of Sleep Medicine review. Sleep. 2007;30(11): 1460-1483.

2. National Sleep Foundation. 2008 Sleep in America Poll. Washington, DC: National Sleep Foundation; 2008.

3. Thorpy MJ, Lieberman JA 3rd, Roth T, Owens GS. Patient identification. Am J Manag Care. 2007;13 Suppl 6:S132-S139.

4. National Heart, Lung, and Blood Institute Working Group on Insomnia. Insomnia: assessment and management in primary care. Am Fam Physician. 1999;59(11):3029-3038.

5. Neubauer DN. Current and new thinking in the management of comorbid insomnia. Am J Manag Care. 2009;15 Suppl:S24-S32.

6. Sateia MJ. Update on sleep and psychiatric disorders. Chest. 2009;135(5):1370-1379

7. Parish JM. Sleep-related problems in common medical conditions. Chest. 2009;135(2):563-572.

8. Pilcher JJ, Ginter DR, Sadowsky B. Sleep quality versus sleep quantity: relationships between sleep and measures of health, well-being and sleepiness in college students. J Psychosom Res. 1997;42(6): 583-596.

9. Newman AB, Spiekerman CF, Enright P, et al. Daytime sleepiness predicts mortality and cardiovascular disease in older adults. The Cardiovascular Health Study Research Group. J Am Geriatr Soc. 2000;48(2):115-123.

10. Elwood P, Hack M, Pickering J, Hughes J, Gallacher J. Sleep disturbance, stroke, and heart disease events: evidence from the Caerphilly cohort. J Epidemiol Community Health. 2006;60(1):69-73.

11. Bixler EO, Vigontzas AN, Lin HM, Calhoun SL, Vela-Bueno A, Kales A. Excessive daytime sleepiness in a general population sample: the role of sleep apnea, age, obesity, diabetes, and depression. J Clin Endocrinol Metab. 2005;90(8):4510-4515.
12. Ferini-Strambi L, Baietto C, Di Giola MR, et al. Cognitive dysfunction in patients with obstructive sleep apnea (OSA): partial reversibility after positive airway pressure (CPAP). Brain Res Bull. 2003;61(1):87-92.

13. Dean B, Aguilar D, Shapiro C, et al. Impaired health status, daily functioning, and work productivity in adults with excessive sleepiness. J Occup Environ Med. 2010;52:144-149.

14. Omachi TA, Claman DM, Blanc PD, Eisner MD. Obstructive sleep apnea: a risk factor for work disability. Sleep. 2009;32(6):791-798.

15. Drake CL, Roehrs T, Richardson G, Walsh JK, Roth T. Shift work sleep disorder: prevalence and consequences beyond that of symptomatic day workers. Sleep. 2004;27(8):1453-1462.

16. Leger D. The cost of sleep-related accidents: a report for the National Commission on Sleep Disorders Research. Sleep. 1994;17(1): 84-93.

17. Flatley D, Reyner LA, Horne JA. Sleep-related crashes on sections of different road types in the UK (1995-2001). London: Department of Transport, Road Safety Research; Report No. 52; 2004.

18. Pandi-Perumal SR, Verster JC, Kayumov L, et al. Sleep disorders, sleepiness and traffic safety: a public health menace. Braz J Med Biol Res. 2006;39(7):863-871.

19. US Department of Transportation. Effects of sleep schedules on commercial motor vehicle driver performance. 2000. Available from: $h$ ttp://www. fmcsa.dot.gov/documents/execsumm-e1.pdf. Accessed Dec 22, 2009.

20. Lopes C, Esteves AM, Bittencourt LRA, Tufik S, Mello MT. Relationship between the quality of life and the severity of obstructive sleep apnea syndrome. Braz J Med Biol Res. 2008;41(10):908-913.

21. Dodel R, Peter H, Noelker C, et al. Health-related quality of life in patients with narcolepsy. Sleep Med. 2007;8(7-8):733-741.

22. Ozaki A, Inoue $Y$, Nakajima $T$, et al. Health-related quality of life among drug-naïve patients with narcolepsy with cataplexy, narcolepsy without cataplexy, and idiopathic hypersomnia without long sleep time. J Clin Sleep Med. 2008;4(6):572-578.

23. Baldwin CM, Griffith KA, Nieto FJ, O'Connor GT, Wasleben JA, Redline S. The association of sleep-disordered breathing and sleep symptoms with quality of life in the Sleep Heart Health Study. Sleep. 2001;24:96-105.

24. Briones B, Adams N, Strauss M, et al. Relationship between sleepiness and general health status. Sleep. 1996;19:583-588.

25. Reimer MA, Flemons WW. Quality of life in sleep disorders. Sleep Med Rev. 2003;7:335-349.

26. Sforza E, Janssens JP, Rochat T, Ibanez V. Determinants of quality of life in patients with sleep-related breathing disorders. Eur Respir J. 2003;21(4):682-687.

27. Chervin RD. Sleepiness, fatigue, tiredness, and lack of energy in obstructive sleep apnea. Chest. 2000;118(2):372-379.

28. Johns MW. A new method for measuring daytime sleepiness: the Epworth sleepiness scale. Sleep. 1991;14(6):540-545.

29. Carskadon MA, Dement WC, Mitler MM, Roth T, Westbrook PR, Keenan S. Guidelines for the Multiple Sleep Latency Test (MSLT): a standard measure of sleepiness. Sleep. 1986;9:519-524.

30. Littner MR, Kushida C, Wise M, et al. Practice parameters for clinical use of the multiple sleep latency test and the maintenance of wakefulness test. Sleep. 2005;28:113-121.

31. American Academy of Sleep Medicine. International Classification of Sleep Disorders. Diagnostic and Coding Manual. 2nd Ed. Westchester, IL: American Academy of Sleep Medicine; 2005.

32. Young T, Palta M, Dempsey J, Skatrud J, Weber S, Badr S. The occurrence of sleep-disordered breathing among middle-aged adults. $N$ Engl J Med. 1993;328(17):1230-1235.

33. Smith IE, Quinnell TG. Pharmacotherapies for obstructive sleep apnoea: where are we now? Drugs. 2004;64(13):1385-1399.

34. Sullivan CE, Issa FG, Berthon-Jones M, Eves L. Reversal of obstructive sleep apnoea by continuous positive airway pressure applied through the nares. Lancet. 1981;1(8225):862-865.

35. Weaver TE, Maislin G, Dinges DF, et al. Relationship between hours of CPAP use and achieving normal levels of sleepiness and daily functioning. Sleep. 2007;30(6):711-719. 
36. Morgenthaler TI, Kapen S, Lee-Chiong T, et al. Practice parameters for the medical therapy of obstructive sleep apnea. Sleep. 2006;29(8):1031-1035.

37. Black JE, Hirshkowitz M. Modafinil for treatment of residual excessive sleepiness in nasal continuous positive airway pressure-treated obstructive sleep apnea/hypopnea syndrome. Sleep. 2005;28(4):464-471.

38. Hirshkowitz M, Black JE, Wesnes K, Niebler G, Arora S, Roth T. Adjunct armodafinil improves wakefulness and memory in obstructive sleep apnea/hypopnea syndrome. Respir Med. 2007;101(3):616-627.

39. Roth T, White D, Schmidt-Nowara W, et al. Effects of armodafinil in the treatment of residual excessive sleepiness associated with obstructive sleep apnea/hypopnea syndrome: a 12-week, multicenter, double-blind, randomized, placebo-controlled study in nCPAP-adherent adults. Clin Ther. 2006;28(5):689-706.

40. Roth T, Rippon GA, Arora S. Armodafinil improves wakefulness and long-term episodic memory in nCPAP-adherent patients with excessive sleepiness associated with obstructive sleep apnea. Sleep Breath. 2008;12(1):53-62.

41. Schwartz JR, Hirshkowitz M, Erman MK, Schmidt-Nowara W. Modafinil as adjunct therapy for daytime sleepiness in obstructive sleep apnea: a 12-week open-label study. Chest. 2003;124(6):2192-2199.

42. Schwartz JR, Roth T. Shift work sleep disorder: burden of illness and approaches to management. Drugs. 2006;66(18):2357-2370.

43. McMenamin TM. A time to work: recent trends in shift work and flexible schedules. Month Lab Rev. Dec 2007:3-15. Available from: http://www. bls.gov/opub/mlr/2007/12/art1 full.pdf. Accessed Oct 15, 2009.

44. Waage S, Moen BE, Pallesen S, et al. Shift work disorder among oil rig workers in the North Sea. Sleep. 2009;32(4):558-565.

45. Czeisler CA, Walsh JK, Roth T, et al. Modafinil for excessive sleepiness associated with shift-work disorder. $N$ Engl J Med. 2005;353(5): 476-486.

46. Czeisler CA, Walsh JK, Wesnes KA, Arora S, Roth T. Armodafinil for treatment of excessive sleepiness associated with shift work disorder: a randomized controlled study. Mayo Clin Proc. 2009;84(11): 958-972.

47. Erman MK, Rosenberg R; for the US Modafinil Shift Work Sleep Disorder Study Group. Modafinil for excessive sleepiness associated with chronic shift-work sleep disorder: effects on patient functioning and health-related quality of life. Prim Care Companion J Clin Psychiatry. 2007;9(3):188-194.

48. Hart CL, Haney M, Nasser J, Foltin RW. Combined effects of methamphetamine and zolpidem on performance and mood during simulated night shift work. Pharmacol Biochem Behav. 2005;81(3):559-568.

49. Longstreth WT Jr, Ton TG, Koepsell T, Gersuk VH, Hendrickson A, Velde S. Prevalence of narcolepsy in King County, Washington, USA. Sleep Med. 2009;10(4):422-426.

50. Wise MS, Arand DL, Auger RR, Brooks SN, Watson NF; for the American Academy of Sleep Medicine. Treatment of narcolepsy and other hypersomnias of central origin. Sleep. 2007;30(12):1712-1727.

51. US Xyrem Multicenter Study Group. A randomized, double-blind, placebo-controlled multicenter trial comparing the effects of three doses of orally administered sodium oxybate with placebo for the treatment of narcolepsy. Sleep. 2002;25(1):42-49.

52. US Xyrem Multicenter Study Group. Sodium oxybate demonstrates long-term efficacy for the treatment of cataplexy in patients with narcolepsy. Sleep Med. 2004;5(2):119-123.

53. Xyrem International Study Group. A double-blind placebo-controlled study demonstrates sodium oxybate is effective for the treatment of excessive daytime sleepiness in narcolepsy. J Clin Sleep Med. 2005;1(4):391-397.

54. Xyrem International Study Group. Further evidence supporting the use of sodium oxybate for the treatment of cataplexy: a double-blind, placebo-controlled study in 228 patients. Sleep Med. 2005;6(5):415-421.

55. Harsh JR, Haydak R, Rosenberg R, et al. The efficacy and safety of armodafinil as treatment for adults with excessive sleepiness associated with narcolepsy. Curr Med Res Opin. 2006;22(4):761-774.
56. US Modafinil in Narcolepsy Multicenter Study Group. Randomized trial of modafinil for the treatment of pathological somnolence in narcolepsy. Ann Neurol. 1998;43(1):88-97.

57. US Modafinil in Narcolepsy Multicenter Study Group. Randomized trial of modafinil as a treatment for the excessive daytime somnolence of narcolepsy. Neurology. 2000;54(5):1166-1175.

58. Wong YN, King SP, Simcoe D, et al. Open-label, single-dose pharmacokinetic study of modafinil tablets: influence of age and gender in normal subjects. J Clin Pharmacol. 1999;39(3):281-288.

59. Wong YN, Simcoe D, Hartman LN, et al. A double-blind, placebocontrolled, ascending-dose evaluation of the pharmacokinetics and tolerability of modafinil tablets in healthy male volunteers. $J$ Clin Pharmacol. 1999;39(1):30-40.

60. Ferraro L, Fuxe K, Tanganelli S, Tomasini MC, Rambert FA, Antonelli T. Differential enhancement of dialysate serotonin levels in distinct brain regions of the rat by modafinil: possible relevance for wakefulness and depression. J Neurosci Res. 2002;68(1):107-112.

61. Mitchell HA, Bogenpohl JW, Liles LC, et al. Behavioral responses of dopamine beta-hydroxylase knockout mice to modafinil suggest a dual noradrenergic - dopaminergic mechanism of action. Pharmacol Biochem Behav. 2008;91(2):217-222.

62. Qu WM, Huang ZL, Xu XH, Matsumoto N, Urade Y. Dopaminergic $\mathrm{D}_{1}$ and $\mathrm{D}_{2}$ receptors are essential for the arousal effect of modafinil. $J$ Neurosci. 2008;28(34):8462-8469.

63. Food and Drug Administration. FDA-approved Labeling Text for NDA 21-875/NUVIGIL TM (armodafinil) Tablets; 2007 June 15. Available from: http://www.accessdata.fda.gov/drugsatfda_docs/ label/2007/021875lbl.pdf. Accessed Oct 15, 2009.

64. Rao Y, Liu ZW, Borok E, et al. Prolonged wakefulness induces experience-dependent synaptic plasticity in mouse hypocretin/orexin neurons. J Clin Invest. 2007;117(12):4022-4033.

65. Beck P, Odle A, Wallace-Huitt T, Skinner RD, Garcia-Rill E. Modafinil increases arousal determined by $\mathrm{P} 13$ potential amplitude: an effect blocked by gap junction antagonists. Sleep. 2008;31(12):1647-1654.

66. Darwish M, Kirby M, Hellriegel ET, Robertson P Jr. Armodafinil and modafinil have substantially different pharmacokinetic profiles despite having the same terminal half lives: analysis of data from three randomized, single-dose, pharmacokinetic studies. Clin Drug Investig. 2009;29(9):613-623.

67. Darwish M, Kirby M, Hellriegel ET, Yang R, Robertson P Jr. Pharmacokinetic profile of armodafinil in healthy subjects: pooled analysis of data from three randomized studies. Clin Drug Investig. 2009;29(2): 87-100.

68. Darwish M, Kirby M, Robertson P Jr, Hellriegel ET. Interaction profile of armodafinil with medications metabolized by cytochrome P450 enzymes 1A2, 3A4 and 2C19 in healthy subjects. Clin Pharmacokinet. 2008;47(1):61-74.

69. Wisor JP, Dement WC, Aimone L, Williams M, Bozyczko-Coyne D. Armodafinil, the $R$-enantiomer of modafinil: wake-promoting effects and pharmacokinetic profile in the rat. Pharmacol Biochem Behav. 2006;85(3):492-499.

70. Dinges DF, Arora S, Darwish M, Niebler GE. Pharmacodynamic effects on alertness of single doses of armodafinil in healthy subjects during a nocturnal period of acute sleep loss. Curr Med Res Opin. 2006;22(1): $159-167$.

71. Black J, Hull SG, Tiller J, Yang R, Harsh JR. Maintenance of efficacy, safety and tolerability of armodafinil: an open-label extension study. Sleep. 2009;32 Suppl:A139 [Abstract No. 0419].

72. Schwartz JR, Khan A, McCall V, Weintraub J, Tiller J. A 12-month or more open-label study of the efficacy and tolerability of armodafinil. Sleep. 2009;32 Suppl:A50-A51 [Abstract No. 0148].

73. Schwartz JR, Becker PM, Tiller J, Bogan RK. Armodafinil improves patient-reported outcomes in patients with excessive sleepiness associated with obstructive sleep apnea or narcolepsy. Sleep. 2009;32 Suppl:A190 [Abstract No. 0580]. 
74. Krystal A, Harsh J, Yang R, Rippon G, Lankford A. A randomised, double-blind, placebo-controlled study with armodafinil in patients with residual excessive sleepiness associated with CPAP-treated obstructive sleep apnoea and comorbid depressive disorders. Poster presented at the 19th Meeting of the European Neurological Society, 2009 June 20-24, Milan, Italy [Abstract No. P353].

75. Akerstedt T, Gillberg M. Subjective and objective sleepiness in the active individual. Int J Neurosci. 1990;52(1-2):29-37.

76. Hull S, Lankford A, Vince B, Niebler GE, Arora S. Armodafinil improves fatigue in patients with excessive sleepiness due to obstructive sleep apnea hypopnea syndrome. Poster presented at the American Psychiatric Association Annual Meeting, 2006 May 25, Toronto, Canada [Abstract No. 127].
77. Russo M. Pharmacotherapy of excessive sleepiness: focus on armodafinil. Clin Med Ther. 2009;1:415-432.

78. Bogan R, Tiller J, Yang R, Youakim J, Roth T. Armodafinil for excessive sleepiness associated with jet lag disorder. Sleep. 2009;32 Suppl:A52 [Abstract No. 0153]

\section{Publish your work in this journal}

Nature and Science of Sleep is an international, peer-reviewed, open access journal covering all aspects of sleep science and sleep medicine, including the neurophysiology and functions of sleep, the genetics of sleep, sleep and society, biological rhythms, dreaming, sleep disorders and therapy, and strategies to optimize healthy sleep. The journal welcomes

\section{Dovepress}

original research, clinical \& epidemiological studies, reviews \& evaluations, case reports and extended reports. The manuscript management system is completely online and includes a very quick and fair peerreview system, which is all easy to use. Visit http://www.dovepress.com/ testimonials.php to read real quotes from published authors.

Submit your manuscript here: http://www.dovepress.com/nature-and-science-of-sleep-journal 